Results Treatment of lipoxin A4 $(100 \mathrm{nM})$ increased the apoptosis of neutrophils $(\mathrm{p}=0.0244)$, and reduced the dead $(\mathrm{p}=0.0238)$ and necrotic neutrophils $(\mathrm{p}=0.0358)$ compared to control $(\mathrm{n}=8)$. BALF from patients with ARDS suppressed efferocytosis of apoptotic neutrophils. The effects of BALF correlated with HMGB-1 levels in the BALF fluid. HMGB-1 decreased efferocytosis $(p<0.05)$ in a dose dependent manner, and reached a significant effect at $150 \mathrm{ng} / \mathrm{ml}(\mathrm{p}=0.008)$. Lipoxin A4 increased the efferocytosis $(p<0.05)$ of alveolar macrophages in a dose dependent manner, and reached the maximal effect at $100 \mathrm{nM}(\mathrm{p}=0.008)$. Moreover, lipoxin A4 (100 nM) blocked the decreased efferocytosis response to HMGB-1 $(150 \mathrm{ng} / \mathrm{ml}) \quad(\mathrm{p}=0.005, \mathrm{n}=8)$. The lipoxin A4 beneficial effects were abrogated by ALX antagonist, BOC-2 ( $<<0.05)$ and PI3K inhibitor $(\mathrm{p}<0.05)$.

Conclusions Lipxin $\mathrm{A}_{4}$ in vitro promotes the apoptosis but not necrosis of neutrophils. In tandem it stimulates efferocytosis of alveolar macrophages. Elevated HMGB-1 in ARDS BALF suppresses efferocytosis. Lipoxin $\mathrm{A}_{4}$ can block these effects of HMGB-1. The effect of lipoxin A4 increasing efferocytosis was through ALX-PI3K signalling pathways. Lipoxin $\mathrm{A}_{4}$ may therefore have potential as a therapeutic agent to promote the resolution of neutrophilic inflammation in ARDS.

\section{COPD outcomes}

\section{S103 NO LOSS IN EFFICACY FOLLOWING SWITCH FROM SALMETEROL/FLUTICASONE COMBINATION TO INDACATEROL MONOTHERAPY IN PATIENTS WITH MODERATE COPD: THE INSTEAD STUDY}

${ }^{1}$ Andrea Rossi, ${ }^{2}$ Thys van der Molen, ${ }^{3}$ Ricardo Del Olmo, ${ }^{4}$ Alberto Papi, ${ }^{5}$ Luis Webhe, ${ }^{6}$ Matthew Quinn, ${ }^{6}$ Chengxing Lu, ${ }^{7}$ David Young, ${ }^{7}$ Ray Cameron, ${ }^{8}$ Enrica Bucchioni, ${ }^{6}$ Pablo Altman. 'Pulmonary Unit, Azienda Ospedaliera Universitaria Integrata, Verona, Italy; ${ }^{2}$ University Medical Center Groningen, University of Groningen, Groningen, The Netherlands; ${ }^{3}$ CIDEA Foundation, Buenos Aires, Argentina; ${ }^{4}$ University of Ferrara, Ferrara, Italy; ${ }^{5}$ Instituto Ave Pulmo, Buenos Aires, Argentina; ${ }^{6}$ Novartis Pharmaceuticals Corporation, NJ, USA; ${ }^{7}$ Novartis Horsham Research Centre, Horsham, UK; ${ }^{8}$ Novartis Farma, Saronno, Italy

\subsection{6/thoraxjnl-2014-206260.109}

Introduction Many patients with low risk of COPD exacerbations receive twice-daily (bid) LABA/ICS, salmeterol/fluticasone (SFC), for maintenance treatment. This study evaluated the effect of switching these patients to a once-daily (od) LABA, indacaterol, monotherapy.

Methods INSTEAD was a 26-week double-blind, double-dummy study in patients aged $\geq 40$ years, with moderate COPD (postbronchodilator $\mathrm{FEV}_{1} \quad 50-80 \%$ predicted) and no exacerbations in the past 12 months, who were receiving SFC 50/500 $\mu \mathrm{g}$ bid for $\geq 3$ months prior to study entry. Patients were randomised (1:1) to continue with SFC 50/500 $\mu$ g or to be switched (with no washout) to indacaterol $150 \mu \mathrm{g}$. The primary objective was to demonstrate non-inferiority of indacaterol to SFC, measured by trough $\mathrm{FEV}_{1}$ after 12 weeks (non-inferiority margin: $60 \mathrm{~mL}$ ). Trough FEV1 was also evaluated at 4, 8 and 26 weeks. TDI and SGRQ-C total scores were evaluated at Weeks 12 and 26; the annualised rate of exacerbations and safety were evaluated over 26 weeks.

Results A total of581 patients were randomised (indacaterol: 293; SFC: 288); 85.4\% completed the study. The primary endpoint was met, with a LSM difference in trough $\mathrm{FEV}_{1}$ between indacaterol and SFC of $-9 \mathrm{~mL}(95 \% \mathrm{CI}:-45$ to $26 \mathrm{~mL}$; $\mathrm{p}=0.002$ for $\mathrm{NI})$. There were no significant differences between treatments in trough $\mathrm{FEV}_{1}$ at any of the other visits (Baseline and Weeks 4, 8 and 26). The TDI and SGRQ-C total scores and their responder rates were similar between two treatments, at both Weeks 12 and 26 (Table 1). During the 26 week treatment period, $79.5 \%$ and $74.7 \%$ of patients in the indacaterol and SFC groups, respectively, experienced no exacerbations. There was no statistically significant difference between treatments in the rate of all COPD exacerbations per year, with rates of 0.57 vs 0.67 , respectively (RR 0.86 [95\% CI 0.62 , 1.20]; $\mathrm{p}=0.367$ ). Adverse events (AEs) and serious AEs were comparable between the treatment arms.

Conclusion Indacaterol was non-inferior to SFC in terms of bronchodilation and showed similar efficacy in terms of breathlessness, health status, and exacerbation rate indicating that this group of patients can be switched from SFC to indacaterol 150 $\mu \mathrm{g}$ with no loss in efficacy.

\section{S104 DOUBLE-BLIND MULTI-CENTRE RANDOMISED CONTROLLED TRIAL OF VITAMIN D3 SUPPLEMENTATION IN COPD (VIDICO)}

${ }^{1} \mathrm{AR}$ Martineau, ${ }^{1} \mathrm{~W}$ James, ${ }^{1} \mathrm{RL}$ Hooper, ${ }^{1} \mathrm{NC}$ Barnes, ${ }^{1} \mathrm{DA}$ Jolliffe, ${ }^{2} \mathrm{~A}$ Bhowmik, ${ }^{1}$ RK Rajakulasingam, ${ }^{3} \mathrm{AB}$ Choudhury, ${ }^{4} \mathrm{DE}$ Simcock, ${ }^{5} \mathrm{CJ}$ Corrigan, ${ }^{5} \mathrm{CM}$ Hawrylowicz, ${ }^{1} \mathrm{CJ}$ Griffiths. 'Queen Mary University of London, London, UK; ${ }^{2}$ Homerton Hospital, London, UK; ${ }^{3}$ Queen's Hospital, Romford, UK; ${ }^{4}$ Royal London Hospital, London, UK; ${ }^{5}$ King's College London, London, UK

\subsection{6/thoraxjnl-2014-206260.110}

Introduction and objectives Inadequate vitamin D status is common in patients with COPD, and it associates with susceptibility to upper respiratory infection (URI) - a major precipitant of exacerbation. Multi-centre trials of vitamin D supplementation for prevention of exacerbation and URI in COPD are lacking. We therefore conducted a multi-centre double-blind randomised placebo-controlled trial of vitamin D supplementation for the prevention of moderate/severe exacerbation and URI in adults with COPD.

Methods Two hundred and forty patients were allocated to receive a 2-monthly oral dose of $3 \mathrm{mg}$ vitamin $\mathrm{D}_{3}$ or placebo for one year. Co-primary outcomes were time to first moderate/

Abstract S103 Table 1 TDI and SGRQ scores

\begin{tabular}{|c|c|c|c|c|c|c|}
\hline & \multicolumn{2}{|l|}{ Week 12} & \multirow[b]{2}{*}{ Treatment difference $(95 \% \mathrm{Cl})$} & \multicolumn{2}{|l|}{ Week 26} & \multirow[b]{2}{*}{ Treatment difference $(95 \% \mathrm{Cl})$} \\
\hline & Indacaterol & SFC & & Indacaterol & SFC & \\
\hline TDI total score & $1.89(0.499)^{\dagger}$ & $1.69(0.509)^{\dagger}$ & $0.20(-0.32,0.72)$ & $2.58(0.543)^{\dagger}$ & $2.70(0.552)^{\dagger}$ & $-0.12(-0.71,0.48)$ \\
\hline SGRQ-C total score & $32.8(1.58)^{\dagger}$ & $32.9(1.61)^{\dagger}$ & $-0.10(-1.9,1.8)$ & $33.1(1.87)^{\dagger}$ & $33.5(1.93)^{\dagger}$ & $-0.40(-2.5,1.6)$ \\
\hline TDI responder ( $\geq 1$ unit), $\%$ & 61.4 & 61.0 & $0.97(0.65,1.46)^{\#}$ & 68.7 & 69.4 & $0.88(0.58,1.35)^{\#}$ \\
\hline SGRQ-C responder ( $\geq 4$ unit),\% & 44.7 & 42.4 & $1.12(0.76,1.63)^{\#}$ & 49.6 & 48.8 & $1.03(0.70,1.52)^{\#}$ \\
\hline
\end{tabular}

${ }^{\dagger}$ Data are LSM (SE): " odds ratio; LSM, least square means; TDI, transition dyspnoea index; SGRQ-C, St George Respiratory Questionnaire for COPD 